\title{
DUST TRANSPORT ACROSS THE ATLANTIC STUDIED BY AIRBORNE DOPPLER WIND LIDAR DURING THE SALTRACE EXPERIMENT IN 2013
}

\author{
Fernando Chouza ${ }^{1 *}$, Oliver Reitebuch ${ }^{1}$, Stephan Rahm ${ }^{1}$, Bernadett Weinzierl ${ }^{1,2}$ \\ ${ }^{1}$ Institut für Physik der Atmosphäre, Deutsches Zentrum für Luft- und Raumfahrt (DLR), \\ Oberpfaffenhofen, Germany, *Email: fernando.chouza@dlr.de \\ ${ }^{2}$ Meteorologisches Institut, Ludwig-Maximilians-Universität München (LMU), München, Germany
}

\begin{abstract}
During the SALTRACE field experiment, conducted during June/July 2013, the Saharan dust transport across the Atlantic was analyzed by a set of ground based, in-situ and airborne instruments, including a $2-\mu \mathrm{m}$ coherent DWL (Doppler wind lidar) mounted onboard the DLR Falcon 20 research aircraft. An overview of the measurements of aerosol backscatter and extinction, horizontal and vertical winds retrieved from the DWL are presented together with a brief description of the applied methods. The retrieved measurements provide direct observation of Saharan dust transport mechanisms across the Atlantic as well as island induced lee waves in the Barbados region.
\end{abstract}

\section{INTRODUCTION}

Mineral dust is a key component of the climate system and the most mass abundant type of aerosol, accounting for about half of the total aerosol mass emissions (e.g. Hinds 1999), acting as cloud and ice nuclei and playing an important role in the radiation budget of the earth.

The Saharan desert has been identified as the world largest source of mineral dust (e.g. Mahowald et al., 2005). Each year, large amounts of Saharan dust are transported across the Atlantic into the Caribbean region (e.g. Prospero, 1999). Despite the progress made during the last decades, the transport mechanisms of the Saharan dust over the Atlantic and their relative importance remain under discussion (e. g. Tsamalis et al., 2013; Karyampudi et al., 1999).

The Saharan Aerosol Long-range Transport and Aerosol-Cloud-Interaction Experiment (SALTRACE: http://www.pa.op.dlr.de/saltrace) conducted during June/July 2013 provided a whole new set of measurements, including in-situ, airborne and ground based observations. For the first time, an airborne coherent DWL was deployed onboard the DLR Falcon 20 research aircraft to study the Saharan dust transport over the Atlantic in combination with an extensive set of in-situ instruments to measure aerosol properties.

The airborne coherent DWLs usually provide the horizontal wind vector and qualitative aerosol measurements. Quantitative aerosol backscatter and extinction profiles were retrieved from the SALTRACE data set by means of a new calibration method (Sec. 3) for the first time. In addition the retrieval of the vertical wind from airborne wind lidar was largely refined (Sec. 4). The simultaneous retrieval of aerosol properties and, horizontal and vertical winds (Sec. 4), enhance the capabilities of the DWL for aerosol transport studies.

\section{INTRUMENTAL DESCRIPTION}

The coherent DWL deployed on the DLR Falcon 20 research aircraft during SALTRACE is based on a CLR Photonics instrument (Henderson et al., 1993) combined with a two wedge scanner and acquisition system developed at DLR (Köpp et al., 2004; Reitebuch, 2012). The system operates at a wavelength of $2.02254 \mu \mathrm{m}$, with a pulse full width at half maximum (FWHM) of $400 \mathrm{~ns}$, a pulse energy of 1-2 $\mathrm{mJ}$, and a repetition frequency of $500 \mathrm{~Hz}$.

When mounted on an aircraft, the system can be operated in two scanning modes: the conical scanning and the nadir pointing mode. The conical scanning mode allows the retrieval of horizontal wind speed vector with a horizontal resolution of around $6 \mathrm{~km}$ (depending on the aircraft speed) and a vertical resolution of $100 \mathrm{~m}$, while the nadir pointing mode can be used to retrieve vertical wind measurements with a horizontal resolution of approximately $200 \mathrm{~m}$ (Sec. 4). Both modes allow, by means of an adequate calibration (Sec. 3 ), the retrieval of backscatter and extinction coefficients with a horizontal resolution of 
approximately $200 \mathrm{~m}$ and a vertical resolution of $100 \mathrm{~m}$.

\section{BACKSCATTER CALIBRATION}

In order to retrieve calibrated backscatter and extinction coefficients from the DWL, a novel calibration method was developed and validated (Chouza et al., 2015).

Based on sun-photometer measurements of the extinction coefficient wavelength dependency and the concurrent measurements of the DWL and a ground based aerosol lidar, calibration constants corresponding to different aerosol types were calculated. Those constants can then be applied to retrieve calibrated backscatter and extinction coefficient profiles at a wavelength of $532 \mathrm{~nm}$ from the coherent DWL measurements during other flight periods.

\section{VERTICAL WIND RETRIEVAL}

Vertical wind can be derived from the DWL measurements. Due to the relatively low magnitude of the vertical winds $\vec{w}$ with respect to the horizontal winds $\vec{V}$ and the Falcon flight speed $\vec{v}_{a c}$, different instrumental corrections have to be applied for the retrieval of the vertical wind in order to reduce the systematic errors introduced by the uncertainties in the DWL pointing direction $\vec{L}$ and the projection of the horizontal winds (Fig. $1)$.

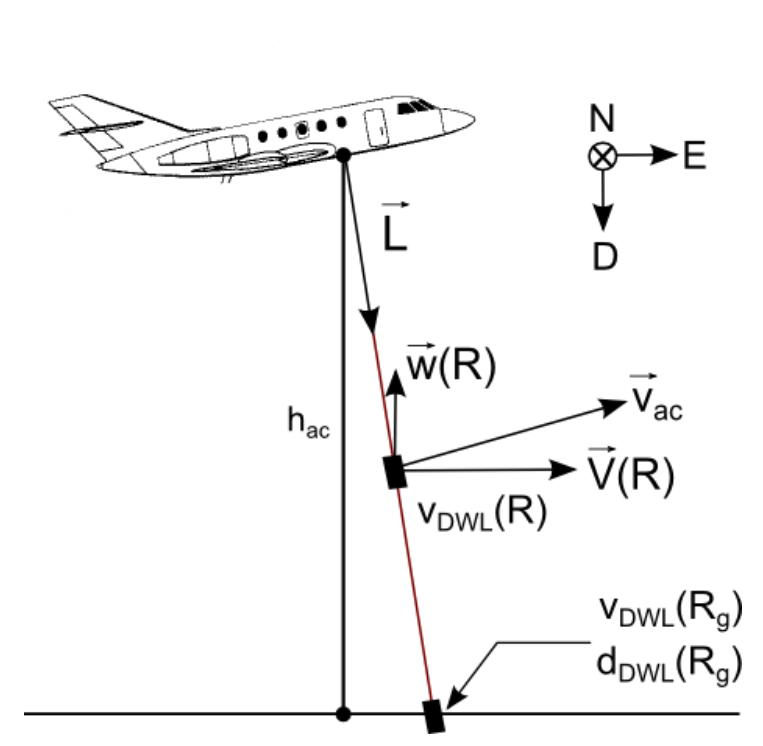

Fig. 1. Sketch of the vertical wind measurements and its various contributors for correction.
The proposed retrieval method is based on a 3steps approach. First, an estimation of the DWL mounting angles and pointing offsets is calculated based on ground return speed $v_{D W L}\left(R_{g}\right)$ and distance $d_{D W L}\left(R_{g}\right)$ from all measurement flights. Then, the residual ground speed error, when available, is subtracted from the LOS speed $v_{D W L}(R)$ for each flight leg. Finally, if horizontal wind speed profiles are available, its projection is calculated and subtracted from the LOS speed.

\section{RESULTS}

Figure 3 shows an example of the retrieved backscatter and extinction coefficients using the method introduced in Sec. 3. The measurements, conducted during a flight on 11 June 2013 from La Palma to Sal (Fig. 2, a), illustrate the northern boundary of the SAL (Saharan Air Layer), its internal structure and the formation of clouds on its top (between 14:22 and 14:43 UTC). As it can be seen from these measurements, the SAL has its lower boundary at around $1 \mathrm{~km}$ and extends vertically up to $7 \mathrm{~km}$ in the Cape Verde region.
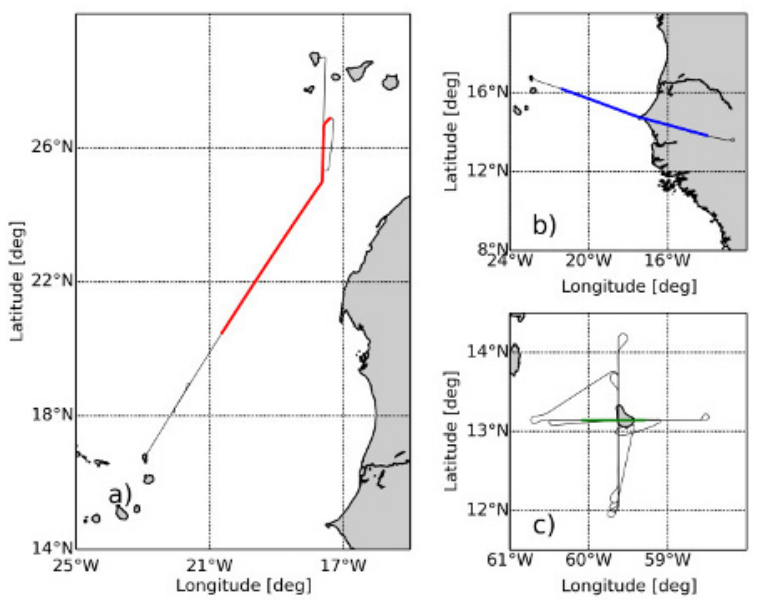

Fig. 2. Flight tracks (black) corresponding to the flights on 11 June between La Palma and Sal (a), 12 June between Sal and Dakar (b) and 26 June around Barbados (c). The colored flight track segments correspond to the measurement sections displayed in Figs. 3-5.

On top of the marine boundary layer (below 1000$500 \mathrm{~m}$ ) clouds are present, which restrict the possibility of backscatter coefficients retrieval below the clouds.

Figure 4 shows the retrieved horizontal wind speed and direction for a flight conducted on 12 
June 2013 between Sal and Dakar (Fig. 2, b). Between 3 and $6 \mathrm{~km}$ altitude a region with high wind speeds (more than $20 \mathrm{~m} \mathrm{~s}^{-1}$ ) is visible, which corresponds to the African Easterly Jet (AEJ). The AEJ is considered to be the main dust advection mechanism associated with the SAL (Karyampudi et al., 1999). In addition to the AEJ, a land-sea breeze system over Dakar (14.72 N, 17.40 W, 9:50 UTC) can also be observed.

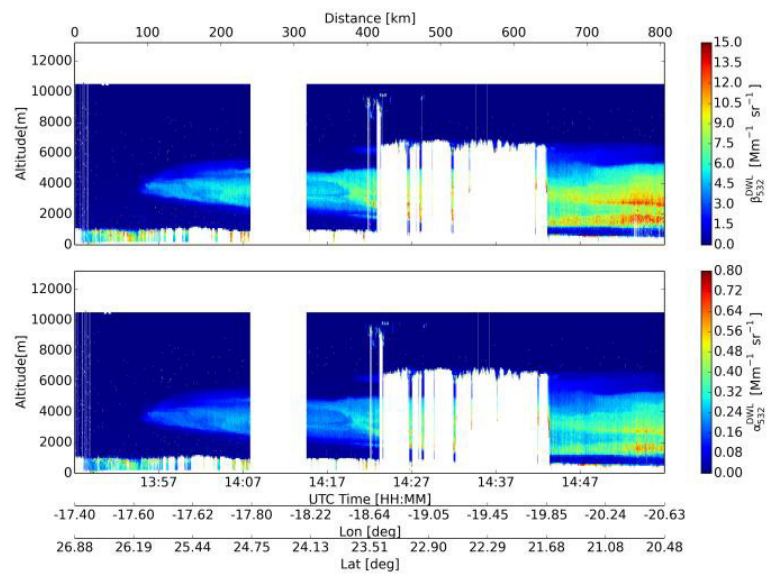

Fig. 3. Retrieved backscatter (upper panel) and extinction coefficients (lower panel) for a flight on 11 June 2013 along the West coast of Africa. The latitude and longitude of the track are shown in the bottom of the figure. An estimated distance scale is shown in the top of the figure. The white color indicates regions were no atmospheric signal is available (e.g. below clouds, low laser energy).

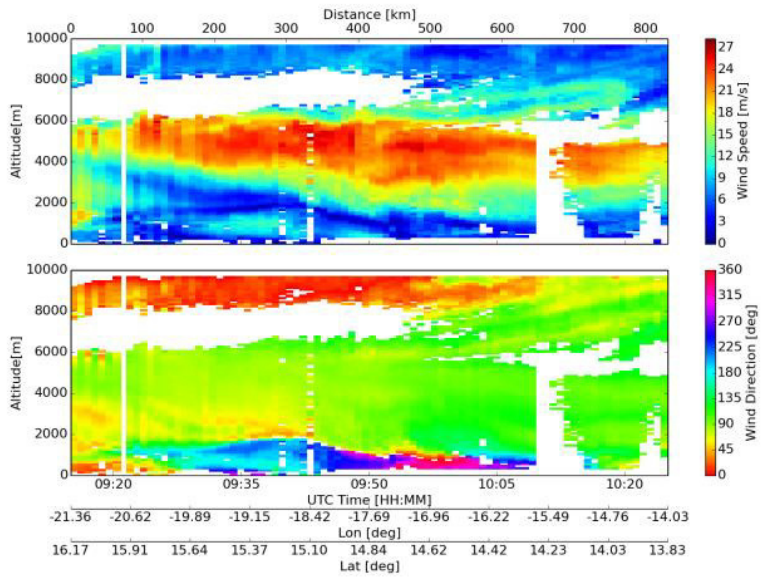

Fig. 4. Retrieved horizontal wind speed (upper panel) and direction (lower panel) for a flight on 12 June 2013 from Sal to Dakar.
Besides the simultaneous retrieval of backscatter coefficients and horizontal winds described in Sec. 2 and Sec. 3, also vertical winds can be obtained from the DWL for flight sections during which the system was operating in nadir pointing mode (Sec. 4). Figure 5 shows an example of the retrieved vertical wind speed and backscatter coefficient for a section (flown eastward) of the flight performed on the 26-27 June 2013 in the Barbados region.

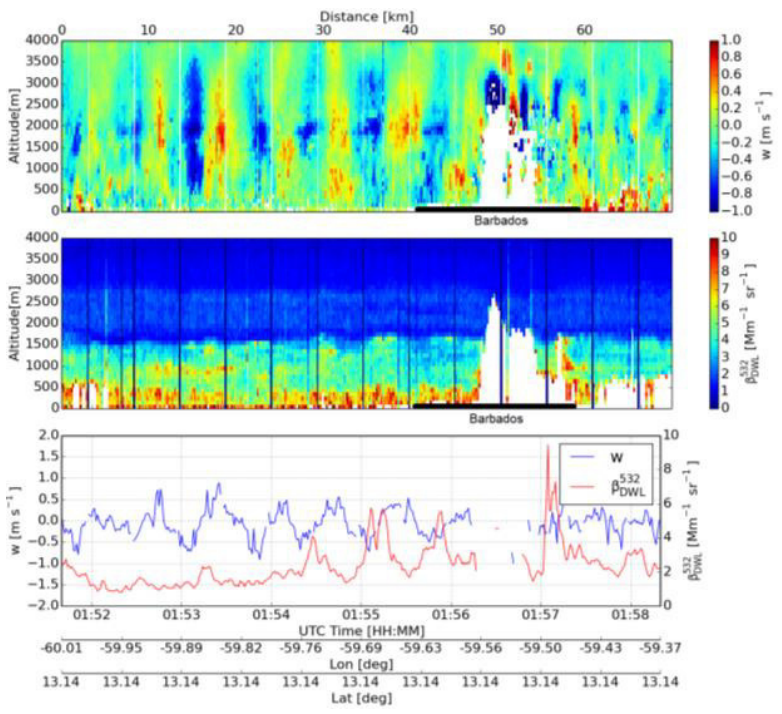

Fig. 5. Retrieved vertical wind speed (upper panel) and backscatter coefficient (mid panel) sections together with the backscatter coefficient and vertical wind for an altitude of $1.5 \mathrm{~km}$ (lower panel) on the lee side of Barbados. Positive vertical winds (red) correspond to upward winds, while negative (blue) winds correspond to downward winds.

Between 1:52 and 1:56 UTC waves with amplitudes of up to $1 \mathrm{~m} \mathrm{~s}^{-1}$ on the lee side of Barbados (overflown between 1:56 and 1:57 UTC) (Fig. 2, c) were observed. The structure of the waves can be also seen in the backscatter coefficient, especially at the boundary between the mixed layer (1000 $\mathrm{m}$ to $1500 \mathrm{~m}$ ) and the SAL (1500 $\mathrm{m}$ up to $4000 \mathrm{~m}$ ), at $1.5 \mathrm{~km}$ (Fig. 4, lower panel). A 90-degrees phase shift between the aerosol backscatter coefficient and the vertical wind velocity is present, which is typical of gravity waves (Durran, 1990). 


\section{SUMMARY}

An overview of the DWL measurement dataset retrieved during SALTRACE was presented. The backscatter and extinction profiles retrieved on the north boundary of the SAL revealed its complex internal structure, vertical extension and shape, while the horizontal wind speed measurements provided a direct observation of the AEJ, associated with the long range transport of Saharan dust. Simultaneous backscatter and vertical wind retrievals exposed the existence of island induced lee waves in the Barbados region.

Further studies using simultaneous backscatter and wind measurements will be performed in order to give us a better understanding of the long range and vertical transport mechanisms associated with the Saharan dust transport over the Atlantic.

\section{ACKNOWLEDGEMENT}

This work was funded by the Helmholtz Association under grant number VH-NG-606 (Helmholtz-Hochschul-Nachwuchsforschergruppe AerCARE). The SALTRACE campaign was mainly funded by the Helmholtz Association, DLR, LMU and TROPOS.

\section{REFERENCES}

[1] Hinds, W.C., 1999: Aerosol Technology: Properties, Behaviour and Measurement of Airborne Particles, John Wiley \& Sons, Inc., New York.

[2] Mahowald, N. M., A.R. Baker, G. Bergametti, N. Brooks, R.A. Duce, T.D. Jickells, N. Kubilay, J.M. Prospero, I. Tegen, 2005: Atmospheric global dust cycle and iron inputs to the ocean, Global Biogeochemical Cycles, 19, 1-15.

[3] Prospero, J. M., 1999: Long-range transport of mineral dust in the global atmosphere: Impact of African dust on the environment of the southeastern United States, Proc. Natl. Acad. Sci. U. S. A., 96, 3396-3403.

[4] Tsamalis, C., A. Chédin, J. Pelon, V. Capelle, 2013: The seasonal vertical distribution of the Saharan Air Layer and its modulation by the wind, Atmos. Chem. Phys., 13, 11235-11257.
[5] Karyampudi, V. M., S.P. Palm, J.A. Reagen, H. Fang, W.B. Grant, R.M. Hoff, C. Moulin, H.F. Pierce, O. Torres, E.V. Browell, S.H. Melfi, 1999: Validation of the Saharan dust plume conceptual model using lidar, Meteosat, and ECMWF data, B. Am. Meteorol. Soc., 80, 1045-1075.

[6] Henderson, S.W., P. Suni, C.P. Hale, S.M. Hannon, J.R. Magee, D.L. Bruns, E.H. Yuen, 1993: Coherent laser radar at $2 \mu \mathrm{m}$ using solidstate lasers, IEEE Trans. Geosci. Remote Sens., 31(1), 4-15.

[7] Köpp, F., S. Rahm, I. Smalikho, 2004: Characterization of Aircraft Wake Vortices by 2$\mu \mathrm{m}$ Pulsed Doppler Lidar, Journal of Atmospheric and Oceanic Technology, 21, 194-206.

[8] Reitebuch, O., 2012: Wind Lidar for Atmospheric Research, in: Atmospheric Physics, Schumann, U., Springer, Berlin Heidelberg, 487507.

[9] Chouza, F., O. Reitebuch, S. Groß, S. Rahm, V. Freudenthaler, C. Toledano, B. Weinzierl, 2015: Retrieval of aerosol backscatter and extinction from airborne coherent Doppler wind lidar measurements, Atmos. Meas. Tech. Discuss., 8, 1935-1986.

[10] Durran, D.R., 1990: Mountain waves and downslope winds. Atmospheric Processes Over Complex Terrain (ed. W.Blumen), Am. Meteorol. Soc., 59-81. 